\title{
The introduction of play specialists as operating department escorts for children.
}

\begin{abstract}
Attending theatre for a surgical procedure can be a very stressful time for both children and their parents and guardians, with ward staff accompanying patients to the operating department to provide support. A local Trust proposed a change from the deployment of registered nurses to the utilisation of play specialists as escorts for children on their journey to theatre and during the induction of anaesthesia to improve patient experience, levels of registered staff remaining on the children's ward and theatre efficiency. It was found that in children who had not received premedication, this substitution can be completed successfully, providing that the play specialists receive sufficient training to carry out this role effectively.
\end{abstract}

\section{Key Words}

Play / Child / Children / Surgery / Anaesthesia / Distraction / Efficiency

\section{Conflict of Interest}

None

\section{Introduction}

This article will discuss the introduction of play specialists in place of registered nurses to accompany children from the ward to the anaesthetic room prior to undergoing surgery. It will include consideration of the concerns which might be felt by members of the perioperative team as a result of this change together with an analysis of the benefits which could be obtained by the introduction of such a scheme.

\section{Discussion}

Undergoing surgery can be a particularly stressful time for both children and their parents or guardians, and anxiety during this period is both undesirable and common (Seiden et al, 2014). Parental accompaniment is an established anxiety-reducing method for children being brought to the anaesthetic room (Wright et al, 2007), as 
separation from parents can be a cause of pre-operative stress for patients (Kain, et al, 1996). Parental presence can also be beneficial for reducing a child's pain score when a painful intervention such as venepuncture is undertaken (Matziou, et al, 2013).

It was usual practice in a local Trust for a registered children's nurse to be provided as an escort to take the child to the anaesthetic room and accompany the parent or guardian from the department after the child had been given their anaesthetic. The use of a nurse to accompany a patient to theatre, however, increased pressure on the practitioners who remained on the wards, and occasionally caused delays in transporting patients to and from surgery which could result in theatre list over runs, and lack of space in the post anaesthetic care unit for admission of further patients.

The local Trust proposed a change from the deployment of registered nurses to the utilisation of play specialists for the accompaniment of children to the theatre department. The aim was to increase the number of qualified staff remaining on the wards without reducing the amount of support provided to the parents and patients attending theatre, while allowing an experienced specialist to help improve the patient's experience through the medium of play. This substitution of staff would only occur where the patient had no additional needs and had received no premedication on the ward, and a qualified practitioner would always accompany a child from the recovery room back to the ward in case of any adverse health event occurring during the post operative journey.

There are many benefits to the use of play within hospitals (Stonehouse, 2014), not least as an important method of communication with children (Elcock and Shapcott, 2015). It can also facilitate familiarisation of children and young people with medical procedures and routines, and provide an escape from stressful situations (Drewes and Schaefer, 2015). Play is also useful for young children who may have had negative previous experiences of being in hospital as well as for those who are unable to verbalise their emotions with regards to previous episodes of hospitalisation (Nabors and Kichler, 2016). It is accepted that adolescents may not be comfortable with play in these situations, and may prefer an approach involving 
talking therapy as distraction techniques should be aimed at the patient's level of cognitive development (Nabors and Kichler, 2016).

When it was proposed at a local Trust that play specialists take over the role of escorts for children attending theatre, many members of theatre staff were concerned that this would not be a change for the better, displaying the attributes of rejecters or change resisters (Rogers and Shoemaker, 1971). Issues raised included whether the specialists would get in the way of the theatre team, and also whether they would be able to deal with emergency situations should these arise during the induction of anaesthesia. This corresponds with the theory suggested by Barr and Dowding (2016) that there will always be team members who are not comfortable with change and who have a low level of tolerance to proposals of new ways of working. This is particularly the case in areas where there has been a pattern involving several changes to practice in a short space of time which was pertinent within this particular department which was at the time experiencing a large amount of change in both procedures and personnel.

To gain more insight into these concerns, a cross section of anaesthetists, theatre nurses and operating department practitioners were asked what they would wish the ward nurse to do in an emergency situation should this arise in an anaesthetic room. Without exception, the expectation was that the nurse would tactfully remove the parent from the anaesthetic room, providing support, and would have no part in handling the crisis itself. There was no expectation, for example, that the accompanying nurse would be involved in drawing up emergency drugs or helping with airway management or resuscitation. This certainly seemed to be a role which could easily be assumed by a play specialist with minimal training and, as the play specialist will already have established a relationship with the patient on the ward by engaging them in play or other activity, they could be seen as being the ideal practitioner to accompany the young person to the anaesthetic room (Bernis, 2015).

The play specialists were then asked to describe the techniques which they would implement when they were in the anaesthetic room and how they planned to ensure that they would not obstruct the theatre staff from carrying out their tasks. They explained that they would be employing distraction techniques, for example bringing 
large books which could be used to obscure the cannulation process from the child's view and also tablet computers to allow the child to look at pictures, watch videos or play an age appropriate game. Distraction using these strategies is a technique already widely employed during medical interventions (Bernis, 2015), and such activities have been shown to be effective in research carried out by Al-Yateem et al (2016) and Seiden et al (2014) and can be considered to be a reliable alternative to the use of pharmacological sedation in this patient group presenting for surgery, particularly if the distraction method is interactive and appropriate to the child's level of development (Wohleiter and Dahlquist, 2013). There were questions raised with regards to whether the play specialists would have the necessary situational awareness to enable them to station themselves in appropriate positions to provide distraction to the child but not obstruct the theatre team from carrying out their duties. Training sessions were therefore carried out with the personnel concerned to ensure that they understood the processes and procedures which take place in an anaesthetic room, and that they could use this knowledge to ensure that they did not hinder access to the child.

Al-Yateem et al, (2016) explain that the experience of undergoing a surgical procedure can be one of the most stressful of a child's life and can result in negative long term consequences ranging from psychological distress to the failure to meet expected developmental milestones if ongoing medical or surgical interventions are required with Lerwick (2013) concurring that failure to address psychological matters can potentially result in negative, long-term psychological issues. Lerwick (2013) lists stressful elements of going to theatre as including separation anxiety, venepuncture, the induction of anaesthesia and concerns about post operative pain. Indeed there appears to be a connection between perioperative anxiety and post operative pain which demonstrates the necessity of intervening to reduce anxiety and thus manage postoperative pain more effectively (Chieng et al, 2014). These assertions are supported by research conducted by Power et al (2012) which found that previous experiences of anxiety and pain following medical procedures can be associated with problematic behaviour persisting past week four of discharge from hospital. Examples of such behaviour issues according to Fortier et al (2010) include eating problems, aggression towards authority figures and sleep disturbance. Al-Yateem et al (2016) go on to suggest that although there has been much discussion around the 
requirement for a greater emphasis on the child's needs during the perioperative period, there has been little research into interventions which might improve a child's experience.

Anxiety and distress have been linked to complications at the time of anaesthetic induction such as the child requiring physical restraint (Wright et al, 2007), and also relate to heightened distress in the post anaesthetic recovery period (Watson and Visram, 2003). These issues are important as such anxiety can obstruct the induction of anaesthesia and have a significant effect on the early stages of postoperative recovery (Kain and Mayes, 1996).

Due to time constraints surrounding the proposed implementation of the scheme, the literature search which was carried out was non-exhaustive and this is acknowledged as a limitation of this study. The evidence found did not furnish much information on the use of play whilst in the theatre department, however the papers which were discovered, agreed that, as suggested by Lerwick (2013), play can support children's emotions around the time of medical and surgical interventions. Lerwick (2013) continues by asserting that numerous studies have shown play to be efficient in the reduction of anxiety in children at this time, and to improve outcomes with Barker (2016) corroborating the use of play as being conducive to the release of stress, the increase in positive thinking and the encouragement of optimism. A randomised controlled trial of 95 children carried out by He et al (2015) demonstrated that children in the group which received play therapy prior to surgery ( $n=48$ ) exhibited significantly less post operative pain and fewer negative emotional manifestations prior to induction of anaesthesia than those children $(n=47)$ in the control group where emotional behaviours can be categorised by facial expression, activity, level of cooperation, vocalisation and interaction ( $\mathrm{Li}$ et al, 2007). It is interesting to compare these results with those from the study carried out by Li et al (2007) which concurs with these findings in relation to the negative emotional aspect, but did not discover significant improvement in post operative pain when play had been employed.

Both of these studies involved children being given the opportunity to act out the two scenarios of a patient being brought to the theatre department and then being given 
an anaesthetic using dolls which was carried out with the children concerned at an outpatient clinic prior to the day of surgery. A small study of children undergoing day surgery in Sweden conducted by Sjöberg et al (2015) discovered that knowledge of what to expect within the perioperative environment coupled with techniques such as the use of electronic entertainment devices for distraction improved the patients' experience.

Perhaps predictably, once the play specialists had been introduced as a 'fait accompli' and they, together with all members of the perioperative team understood the roles and responsibilities assigned to each team member, their presence in the department was accepted and soon became the norm. There were some issues with implementation initially with several instances of play specialists failing to judge the correct place to stand, and when they needed to step back to allow the theatre staff to carry out their interventions. This improved greatly in time, and they have now been accepted as a useful member of the perioperative team as suggested by Shields (2010). In fact, as the play team are not available for evening, night or weekend shifts, their absence is keenly felt at those times. Lerwick (2013) is of the opinion that paediatric surgeons could be instrumental in lobbying budget holders to provide more funding for play specialists which could lead to them being employed outside their current restricted schedules and available to help address the anxieties of more patients.

With regards to the number of delays experienced due to registered nurses being unavailable as a result of their attendance in anaesthetic rooms, no robust data was collected, however the general consensus was that this improved. There was also more flexibility, as when the play specialists were already accompanying a patient to theatre, if another patient was sent for from the ward, a nurse could perform this role if there was capacity for them to do so. Previously, when only nurses accompanied patients, the absence of a member of staff from the ward due to escorting another patient to the operating department would often result in delays of up to half an hour whilst waiting for them to return.

\section{Conclusion}


It is the duty of all health professionals to give their patients the best possible care from both physical and psychological perspectives (McAlister, 2010), and it is essential for humanitarian reasons that children should be spared the anxiety associated with the perioperative period as much as possible (Watson and Visram, 2003). It seems that the introduction of play specialists in the anaesthetic room prior to surgery can be a positive step towards achieving this, provided that these practitioners have received adequate training and do not obstruct the work of the theatre team and that the patients have not been given any premedication. In addition, it appears that theatre efficiency and registered nurse presence on the children's ward could be improved by the inclusion of play specialists in the practice of escorting these patients to the operating department, however more research would need to be carried out to support this hypothesis.

\section{References}

Al-Yateem N, Brenner M, Shorrab AA, Docherty C 2016 Play distraction versus pharmacological treatment to reduce anxiety levels in children undergoing day surgery Child: Care, Health and Development, 42 (4), 572-581 doi:10.1111/cch.12343

Barker S 2016 Psychology for Nursing \& Healthcare Professionals London, Sage

Barr J, Dowding L 2016 Leadership in Health Care $\left(3^{\text {rd }}\right.$ ed) London, Sage

Bernis KS 2015 Play Therapy in Medical Settings. In: O'Connor KJ, Schaefer CE Braverman LD (eds) 2015 Handbook of Play Therapy (2 ${ }^{\text {nd }}$ ed.) Hoboken, John Wiley \& Sons, Inc. doi:10.1002/9781119140467

Chieng Y, Chan W, Klainin-Yobas P, He H 2014 Perioperative anxiety and postoperative pain in children and adolescents undergoing elective surgical procedures: a quantitative systematic review Journal of Advanced Nursing 70 (2) 243-255. doi:10.1111/jan.12205

Drewes A A, Schaefer CE 2015 The Therapeutic Powers of Play. In: O'Connor KJ, 
Schaefer CE, Braverman LD (eds) Handbook of Play Therapy (2nd ed.) Hoboken, John Wiley \& Sons, Inc. doi:10.1002/9781119140467

Elcock K, Shapcott J 2015 Core Communication Skills. In: Delves-Yates C (ed) Essentials of Nursing Practice London, Sage

Fortier MA, Del Rosario AM, Rosenbaum A, Kain ZN 2010 Beyond pain: Predictors of postoperative maladaptive behavior change in children Paediatric Anaesthesia, 20 (5) 445-453. doi:10.1111/j.1460-9592.2010.03281.x

He H, Zhu L, Chan SW et al 2015 Therapeutic play intervention on children's perioperative anxiety, negative emotional manifestation and postoperative pain: $A$ randomized controlled trial Journal of Advanced Nursing 71 (5) 1032-1043. doi:10.1111/jan.12608

Kain Z, Mayes L 1996 Anxiety in children during the perioperative period. In: Borestein MH, Genevro JL (eds) Child Development and Behavioural Paediatrics Mahwah NJ, Lawrence Erlbaum Associates Publishers

Kain Z, Mayes, L O'Connor, T Cichetti D 1996 Preoperative anxiety in children: predictors and outcomes Archives of Paediatrics and Adolescent Medicine 150 (12) 1238-1245. doi:10.1001/archpedi.1996.01270370016002

Lerwick JL 2013 Psychosocial implications of pediatric surgical hospitalization Seminars in Pediatric Surgery 22 (3) 129-133. doi:10.1053/j.sempedsurg.2013.04.003

Li WHC, Lopez V, Lee TLI 2007 Effects of preoperative therapeutic play on outcomes of school-age children undergoing day surgery Research in Nursing \& Health 30 (3) 320-332. doi:10.1002/nur.20191

Matziou V, Chrysostomou A, Vlahioti E, Perdikaris P 2013 Parental presence and distraction during painful childhood procedures British Journal of Nursing 22 (8) 470475. doi:10.12968/bjon.2013.22.8.470 
McAlister W 2010 Anaesthesia in Children In: Shields L (ed) Perioperative Care of the Child: A Nursing Manual Chichester, Wiley- Blackwell

Nabors L, Kichler J 2016 Play Therapy With Children Experiencing Medical Illness and Trauma In: O'Connor KJ Schaefer CE Braverman LD (eds) Handbook of Play Therapy (2nd ed.) Hoboken, John Wiley \& Sons, Inc. doi:10.1002/9781119140467

Power NM, Howard RF, Wade AM, Franck LS 2012 Pain and behaviour changes in children following surgery Archives of Disease in Childhood 97 (10) 879-884. doi:10.1136/archdischild-2011-301378

Rogers EM, Shoemaker FF 1971 Communication of innovations: A cross-cultural approach $\left(2^{\text {nd }}\right.$ ed) New York, Free Press

Seiden SC, McMullan S, Sequera-Ramos L et al 2014 Tablet-based interactive distraction (TBID) vs oral midazolam to minimize perioperative anxiety in pediatric patients: A noninferiority randomized trial Pediatric Anesthesia 24 (12) 1217-1223. doi:10.1111/pan.12475

Shields L 2010 The psychosocial care of children in the perioperative area. In: Shields L (ed) Perioperative Care of the Child: A Nursing Manual Chichester, WileyBlackwell

Sjöberg C, Amhliden H, Nygren JM et al 2015 The perspective of children on factors influencing their participation in perioperative care Journal of Clinical Nursing 24 (1920) 2945-2953. doi:10.1111/jocn.12911

Stonehouse D 2014 Support workers have a vital role to play in play British Journal of Healthcare Assistants 8(3) 137-139 doi:10.12968/bhja.2014.8.3.137

Watson AT, Visram A 2003 Children's Preoperative Anxiety And Postoperative Behaviour Paediatric Anaesthesia 13 188-204. doi: 10.1046/j.14609592.2003.00848.x 
Wohlheiter KA, Dahlquist LM 2012 Interactive Versus Passive Distraction for Acute Pain Management in Young Children: The Role of Selective Attention and Development Journal of Pediatric Psychology 38 (2) 202-212. doi: 10.1093/jpepsy/jss108

Wright KD, Stewart SH, Finley GA, Buffet-Jerrott SE 2007 Prevention and intervention strategies to alleviate preoperative anxiety in children Behaviour Modification 31 (1) 52-79. doi: 10.1177/0145445506295055 